\title{
Business strategy and blockchain adoption
}

\author{
Jiangbo Huangfu \\ Florida Atlantic University \\ jhuangfu2017@fau.edu
}

\author{
Robert Pinsker \\ Florida Atlantic University \\ rpinsker@fau.edu
}

\author{
Hanbing Xing \\ Florida Atlantic University \\ hxing2019@fau.edu
}

\begin{abstract}
Although blockchain has drawn significant attention since its introduction in 2008, determinants of its adoption remain largely unknown. Relying on the Resource-Based View (hereafter, RBV) of the firm as a theoretical guide, we investigate whether a firm's business strategy affects its decision on blockchain adoption. We split firms into prospectors (risk takers) and defenders (interested in cost stability) consistent with the business strategy framework to determine if the former group is more likely to adopt blockchain.

Using a sample of 208 firms from 2015 to 2019, we find that prospectors are more likely to adopt blockchain than defenders. Results suggest blockchain brings more net benefits to prospectors than to defenders. The results support RBV and business strategy theories and are robust to the consistency test, factor analysis, and placebo test. The findings imply that the alignment between business strategy and technology characteristics motivates firms to adopt specific technology.
\end{abstract}

\section{Introduction}

Miles and Snow's [1] business strategy framework identifies business strategies as a continuum between prospector and defender approaches as an identity that firms use to differentiate themselves from peers. Prospectors follow an innovation strategy, aggressively pursue new market opportunities, are risk-taking, and have diverse operations, complex structures, and thus more decentralized control structure than defenders (e.g. 3M, Johnson \& Johnson, Tesla Motors). Defender firms follow a cost leadership strategy, are risk-averse, and have centralized decision making (e.g. BIC Corporation, Mrs. Fields Inc., Tower International, Inc.) [1]-[4]. Prior research finds that firms' business strategy is associated with firm's information technology (IT) policy, and the alignment between business strategy and technology policy further improves economic performance [5]-[8].
Blockchain technology provides a unique opportunity to test the business strategy framework in the context of IT adoption. Blockchain could transform a firm's business model, improving operations [9], but at the same time, it presents risks and uncertainties as a new IT. Examining the business strategy framework [1] in the context of blockchain adoption, prospector firms should be more willing to take the adoption risks than defender firms, because the benefits are more closely aligned with the former group (i.e., innovative, risktaking, decentralized decision-making).

Resource Based View (RBV) of the firm adds an additional, theory-based perspective for studying this phenomenon. RBV suggests that firms explore external opportunities that can achieve core competitive advantage in the market [10]. Both RBV theory and empirical evidence suggest that if IT is integrated with firm's unique and complementary internal resources, it could deliver superior business value [11]-[15]. These arguments further support increased blockchain adoption likelihood in prospector firms vis-à-vis defender firms.

The purpose of this study is to investigate the effect of firm's business strategy on blockchain adoption. Examining the relationship between the business strategy framework [1] and blockchain adoption would fill an important gap in the related academic research. Prior management information systems research mainly focuses on the alignment between IT policy and firms' innovation strategy, cost efficiency, and risk-bearing level [5], [7], [8], [15]. The unique decentralization feature of blockchain [16], [17] potentially provides firms an additional "fit" to their pre-existing decisionmaking structure. Such additional fit differentiates firm's blockchain adoption decision from firm's general IT and innovation strategies, which could be inherently pre-determined by business strategy at early stage of business. Thus, our study provides additional evidence on the effect of business strategy on firms' technological competence and operational decision.

Anecdotally, the proclaimed advantages and importance of blockchain and current adoption status do 
not clearly reconcile. Although blockchain was expected to be part of a revolution to disrupt the global economy[17]-[21], the adoption of blockchain in the private sector has been slow [19]. Guo et al [22] provide initial insights on several internal and external factors that affect blockchain adoption, including innovation level, agency costs, and external monitoring effects, but additional research on the topic is needed if blockchain is to fulfill its promised benefits.

Empirically, we follow Miles and Snow [1] and Hsieh et al [23] to calculate a strategy composite and identifying prospector and defender firms. We find that prospector firms are more likely to adopt blockchain than defenders. Consistent with RBV, prospectors are more likely to explore blockchain, because it results in more core competitive advantages in the market than defenders, due to the alignment between blockchain and prospector strategy characteristics. The results are robust to testing for endogeneity, factor analysis, and a placebo test.

The remainder of this study is organized as follows. Section 2 reviews the relevant literature and develops the hypotheses. We then describe the sample and research design in Section 3. Section 4 describes the empirical results, and Section 5 provides additional analyses. Section 6 concludes the study.

\section{Literature review and hypothesis development}

\subsection{Business strategy}

The extant management literature proposes various business strategy typologies to identify how firms compete in a given industry or market environment to achieve a high level of performance[24]-[30]. Common business strategies include rate of change to market view [1], product differentiation view [25], exploration view[29], and cost leadership [30]. Specifically, Miles and Snow [1] identify three viable business strategies: prospector, analyzer, and defender based on the firm's rate of change in response to the respective products and markets. ${ }^{1}$ Porter [25] classifies firms' business strategy into cost leadership and product differentiation. March [29] classifies business strategies into exploration and exploitation and Treacy and Wiersema [30] identify business strategies as operational excellence, product leadership, and customer intimacy.

Among various business strategies typologies, Miles and Snow's [1] work is widely recognized and most likely to align with inferences based on the other

\footnotetext{
${ }^{1}$ The fourth strategy, reactor, is not viable and sustainable in the long term, because reactors simply react to pressures in the business environment forces (McDaniel and Kolari 1987). Hence, reactors
}

typologies [4], [27], [31], [31]-[36]. The prospector classification can be aligned with the product differentiation typology by Porter [25], exploration type in March [29], product leadership type in Treacy and Wiersema [30]; whereas, the defender classification is aligned with cost leadership type in Porter [25], exploitation type in March [29], operational excellence type in Treacy and Wiersema [30].

Based on Miles and Snow's [1] framework, prospector and defender firms (henceforth, prospectors and defenders, respectively) are the two endpoints of the business strategy continuum. Specifically, prospectors focus on exploring new products or market opportunities through innovation. Defenders focus on efficiency in the production and distribution of goods and services and succeed in penetrating a narrow market. Analyzers are firms that have the characteristics of both prospectors and defenders depending on their technology efficiency and business environment, for example, being more risk-aversion than prospectors but also more aggressively pursuing new opportunities than defenders [1]. Prior literature mainly focuses on the two endpoints of continuum, prospector and defender, because they are the most distinguishable in organization characteristics [2], [4], [23], [31], [37], [38]. Therefore, following prior literature, we limit our focus on the prospector and defender strategies, since these two strategies differ drastically in terms of their technology strategy, investment horizon, risk-bearing level, and organizational structure.

Prior research documents evidence on the systematic difference of firms' operating and reporting environment among different business strategies. Lim et al [39] find that business strategies affect firm's operating complexity, environmental uncertainty, and information asymmetry. Specifically, prospectors have less readable disclosures than defenders due to higher exposure to operating complexity and environmental uncertainty. Similarly, Zhang [40] finds that prospectors have less stock price informativeness than defenders. Bentley-Goode et al [41] find that prospectors are more likely to have weaker internal controls than defenders. Bentley et al [4] find that prospectors are more likely to experience financial reporting irregularities and require more audit effort. Hsieh et al [23] find that prospectors face greater ambiguity and report more conservatively than defenders. Collectively, prospectors are more likely to have uncertainties in the information environment and irregularities in their operational processes than defenders, which could represent a greater need for blockchain.

lack a consistent strategy, and is often difficult to identify due to the ambiguous and inconsistent behavior. Therefore, we focus on only the viable strategies. 
The prior literature also describes how business strategy affects firm's decision-making processes, including innovation choices. For example, Higgins et al [31] find that prospectors are more likely to engage in tax avoidance than defenders due to their higher risk bearing. Yuan et al [42] find that compared with defenders, prospectors are more likely to take advantage of corporate social responsibility due to their innovation-oriented strategy, risk-bearing, and longterm horizon. Specific to innovation choices, Gosselin [43] finds that prospectors who have structures that adapt to unpredictable and uncertain environments are more likely to adopt IT innovations than defenders. Blumentritt and Danis [44] find that prospectors put more effort into innovation adoption than defenders in order to sustain their competitive position. In sum, the extant literature provides some support for business strategy as an important determinant in innovation (IT adoption) decisions.

\subsection{Resource-based view of the firm}

The RBV of the firm suggests that firms utilize internal and external resources to explore external opportunities that can achieve, maintain, and improve their competitiveness [10]. Firms' ability to achieve strategic fit among the internal and external competitive factors facilitates high performance. Such strategic fit requires alignment of organizational resources, capabilities, and competencies with environmental opportunities and threats [24], [45]. Firms have heterogenous resources, skills, and capabilities, thus, they potentially have different strategies competing with one another.

RBV theory implies that if valuable resources or capabilities of the firm can be easily substituted or imitated by others, it is unlikely that such resources or capabilities could create sustainable competitive advantages [10], [46]. Based on this theory, if IT could be intimated by competitors, the firm may not enjoy sustainable advantages. However, by integrating IT with the firm's unique and complementary internal resources, the IT could deliver superior business value [11]-[15], [47]. Accordingly, prior research finds a positive correlation between strategic alignment, the alignment between IT and business strategy [6], [48], [49], and firm performance for prospectors. However, defenders fail to realize benefit from the alignment [50].

\subsection{Blockchain}

Blockchain technology was first used by Nakamoto [16] as the IT underlying Bitcoin. Blockchain is a decentralized public ledger that provides a secure infrastructure for transactions among parties without a central authority [16]. The main characteristics of blockchain are decentralization, strong authentication, and tamper-resistance. Decentralization allows all the nodes in the system to have access to the entire list of information and allow nodes to verify and publish new information. Blocks are then periodically appended to the end of the blockchain with a timestamp [16]. Although in the initial bitcoin system, all users have the authority to view, write, and update the information to the chain, in many modern applications of blockchain in business, namely, private blockchain, each user is preassigned with permissions.

The nascent literature identifies various benefits and shortcomings of blockchain. In terms of perceived benefits, blockchain is expected to improve business process transparency [51]. The blockchain-based smart contract can mitigate information asymmetry, enhance market entry and competition, and improve consumer surplus [21]. The decentralized nature of blockchain implies a database management system without a central authority, resulting in a potential revolution in the financial industry [52]. For shareholders, blockchain records stock ownership and improves shareholders' participation in the firm [53]. For auditors, blockchains improving clients' information security and improves process efficiency, and further reduce clients' misreporting incentives [20].

Compared with other database management systems and technologies, major advantages of blockchain are decentralization and immutability. Blockchain decentralizes the power of verification, storage, and updates to a group of computers [54], mitigating the potentially large issue of competing database management system that such systems are still heavily dependent on their centralized database. Such a decentralized mechanism could vastly reduce the risk of a single point computer failure [17] and, at the same time, strictly constrained unauthorized change, manipulation, or override in the system. Blockchain is potentially more efficient in structure with an appendonly, linear transactional database [54] and operates with little human intervention [17], [55].

Conversely, blockchain adoption also brings on various concerns. Although blockchain could increase process transparency and facilitate information sharing, greater information sharing could result in undesirable proprietary costs to firms [54]. Further, the cost and risk of switching to blockchain could be significant to firms, because of challenges on necessary physical infrastructure, technical challenges, regulation uncertainties, and organizational suitability [56].

\subsection{Hypothesis development}


Based on RBV theory, the blockchain adoption decision depends on whether blockchain can bring unique, non-substitutable core competitive advantages in the market with existing firm strategies. Consistent with both RBV theory and the previous business strategy arguments, prospectors are more likely than defenders to adopt blockchain for the following reasons. First, prospectors focus on innovation and compete on new products and new market opportunities that can build competitive advantages in the market. Blockchain helps build core competitive advantages for firms, such as improving the business process transparency [51], mitigating information asymmetry [21], improving intra-firm collaborations [57], and, most importantly, significantly reducing manipulative opportunities and manager override by its unique decentralized nature, and thus improving firm's internal controls [54]. Second, prospectors are risk-bearing and are better equipped to solve uncertainties resulting from new technology adoption, compared with defenders who are riskaversion and pursue cost stability. Blockchain, as an emerging technology that are still at early stage of implementation and has few actual application cases, still have uncertainties and risks at adoption, such as infrastructure challenges, business suitability, probability of unsuccessful implementation, and regulatory uncertainty [54]. Therefore, prospectors are more likely to bear and resolve the risks associated with blockchain adoption than defenders.

Third, blockchain meets the demand of prospectors in improving monitor of the decentralized organizational structure. Due to the broad product portfolio and marketing, prospectors often have diversified business operations and numerous operation segments, resulting a decentralized organizational control, a more relaxed corporate governance, higher likelihood of weaker internal control, and more unethical behavior and financial reporting irregularities [4], [41], [58], [59]. Otley [60] and Dermer [61] suggest that firm's control system should be designed specifically to suite the business strategy of the firm.

Finally, blockchain's decentralized and immutable system is consistent with the broad architecture of prospectors. The alignment between business strategy and IT strategy contributes to the perceived business performance for prospectors [49], [62]. Thus, by adopting blockchain, prospectors could be perceived as innovators in the market, facilitate business performance, and achieve efficiency and competitiveness. Therefore, in sum, prospectors are likely to adopt blockchain technology due to its core competitive advantages, risk-taking nature of prospector business strategy, and organizational structure alignment.
We argue that defenders are less likely to adopt blockchain for the following reasons. First, defenders pay more attention to technology efficiency of blockchain. The firms tend to follow a costminimization strategy and pursue efficiency in producing and distributing goods and services. To achieve high efficiency in production and distribution, defenders focus on technological efficiency instead of technological flexibility. While blockchain technologies bring various benefits, significant costs related to blockchain, including substantial challenges in establishing infrastructure and high switching costs, could hinder its technological efficiency [54] and thus reduce defenders' incentives to adopt.

Second, defenders are more risk-inverse [1]. Thus, they are more likely to avoid the risk and uncertainties like unsuccessful technology development and regulatory uncertainties associated with early-stage adoption of blockchain. Third, because defenders focus on a narrow market and interrelated product portfolio, their organizational control environment is often centralized, inconsistent with the decentralized nature of blockchain. In aggregate, concern about technology efficiency of blockchain, risk inversion, and misalignment between organizational structure and blockchain nature, are all arguments consistent with defenders being less likely to adopt blockchain.

However, regardless of the alignment between prospector characteristics and blockchain features, prospectors could still be hold back by the proprietary costs from blockchain adoption. Increased information sharing of blockchain brings potential increased proprietary costs. The proprietary cost could be especially high for prospectors because prospectors gain competitiveness from new products and markets, containing more proprietary information than a narrow and mature market for defenders. Therefore, a significant increase in proprietary cost may reduce the cost-benefit efficiency of blockchain adoption and hinder prospectors' incentives to adopt blockchain.

Given the above discussion comparing prospectors and defenders, and the related arguments stemming from the business strategy framework [1] and RBV of the firm [10] literatures, we hypothesize following:

H1: Prospectors are more likely to adopt blockchain than defenders.

Based on Miles and Snow [1] business strategy framework, prospectors focus on technology flexibility while defenders focus on technology efficiency. Prospectors pursue technology flexibility to react to new opportunities and market rapidly. However, due to the cost of technology implement and associated risks, prospectors are hard to achieve technology efficiency. Defenders focus on the cost efficiency of its technologies [1]. Different business strategy results in 
the variation in technology policy, and hence affects the technology decision making. Therefore, we investigate whether the technology efficiency is one of the channels that business strategy affects blockchain adoption.

H2: Firms that have higher technology efficiency are less likely to adopt blockchain.

\section{Research design}

\subsection{Sample Selection}

We hand-collected a sample of blockchain adoptions from the fiscal year 2015 to 2019 . We first searched for firms' 6-K, 8-K, 8-K, 10-K, 10-Q, 20-F, $40-\mathrm{F}$ filings and identify those that have disclosure contains the words "blockchain" and "block chain." we then review each document to determine whether the firm actually adopts blockchain and the date or month of adoption. We select the earliest mention of blockchain adoption if mentions in multiple documents occur. After initial disclosure, we treat the firm as adopted even if no further disclosure is made, unless additional disclosure specifically mentioned the firm stops blockchain implementation. Blockchain adoption firms are matched to Compustat and Audit Analytics by Central Index Key (CIK). The final blockchain adoption sample includes 208 blockchain adopting firms from the fiscal year 2015 to 2019. After including all nonblockchain adopting firm-year observations with all available financial information to construct variables, the initial sample consists of 10,965 firm-year observations.

\subsection{Measurements}

Following Guo et al [22] and Cheng et al. [18], we define blockchain as an indicator variable that equals 1 starting the year that the firm discloses actual adoption of blockchain, and zero otherwise.

Following Bentley et al [4], Higgins et al. [31], and Hsieh et al [23], we construct the composite business strategy measure using six firm characteristics: (1) the ratio of $\mathrm{R} \& \mathrm{D}$ expense to total sales, (2) the ratio of employees to sales, (3) the one-year sales growth rate, (4) the ratio of selling, general, and administrative expenses to total sales, (5) the standard deviation of the number of employees, and (6) net property, plant, and equipment scaled by total assets. We calculate all six variables using a rolling five-year average and then rank each variable into quintiles within each Fama-French 12 industry-year to minimize the effect of industry driven factors. For example, certain industries have higher ratios in general, such as pharmaceutical firms, which would be considered more risky than utility firms. Firms with the highest value (top quintile) are assigned with a score of 5, while the lowest quintile firms are assigned a score of 1. For each firm year, we add up the scores for each of the six variables. The sum of scores is STRATEGY measure, which ranges from 6 (all six factors are ranked as 1) to 30 (all six factors are ranked as 5). A higher value of STRATEGY indicates that firms follow the prospector strategy; whereas, a lower value of STRATEGY indicates that firms follow the defender strategy. Following Hsieh et al (2018), we further create a dummy variable (PROSPECTOR) that equals one if the score is greater than 18 and zero otherwise.

we then match prospector firms with defender firms with the propensity score matching method as shown in Eq. (1). Matching by propensity score can potentially eliminate a great portion of biased treatment effects and create a balanced dataset, allowing a direct comparison of baseline covariates between prospector and defender. We use caliper matching with the width of 0.01 and without replacement to match prospector to defender firms [63]-[65]. Accordingly, we fit a first-stage logistic regression that matches the prospector and defender as a function of firm fundamental and performance control variables in Eq. (1).

Following Guo et al [22], we control for firm size, which equals to natural logarithm of firm's total assets, and firm profitability, including return on assets and loss. Return on assets equals to firms' income before extraordinary items scaled by firm's total assets in current fiscal year. Loss equals 1 if firm suffer a negative income in the current year and 0 otherwise. We also control for firm's growth opportunities - market to book ratio, which equals the ratio of firm's market value of equity to firm's book value of equity. We further control firms' leverage ratio, tangibility ratio, and operating cash flow to control for firm's financial health condition, where leverage ratio equals to firms' total debt divided by total assets, tangibility ratio equals ratio of net property, plant, and equipment to total assets, and operating cash flow equals to firms' operating cash flow scaled by total assets. Lastly, we control for firm's innovation investment, R\&D by control firm's R\&D expenses scaled by lagged total assets. Further, we control year and Fama-French 12 industry fixed effects to mitigate the impact of time-invariant year and industry characteristics are also included.

$\operatorname{Pr}($ Prospector $=1)=\beta_{0}+\beta_{2}$ SIZE + $\beta_{2}$ ROA $+\beta_{3}$ LOSS $+\beta_{4}$ MTB $+\beta_{5}$ LEVERAGE + $\beta_{6}$ TANG $+\beta_{7} \mathrm{OCF}+\beta_{8} \mathrm{RD}+\varepsilon$

All variables are statistically significant $(\mathrm{p}<0.01)$ in the PSM model. After matching, the difference between prospectors and defenders on fundamental variables are no longer significant except MTB ratio and LOSS, which are expected because prospectors are more likely to have growth opportunities and unstable profitability 
compared with defenders [1]. Following propensity score matching, the final sample consists of 7,237 firmyear observations including 146 blockchain adoption firms.

Following Chan et al [66] and Lev et al [67], we proxy technology efficiency as the ratio of the number of patent granted to the total R\&D capital spent. Specifically, technology efficiency is defined as the ratio of firm i's patents granted in year $t$ (Patents $s_{i, t}$ ) scaled by the 5-year cumulative R\&D expenses assuming an annual depreciation rate of $20 \%$. We set missing R\&D in Compustat to zero and allow a 2-year gap between R\&D capital and patents issuance because of the average 2-year granting period of USPTO (Hall, Jaffe, and Trajtenberg, 2001).

Technology Efficiency $=$ Patents $_{i, t} /\left(R_{R} \& D_{i, t-2}+0.8 R \& D_{i, t}\right.$ $\left.{ }_{3}+0.6 \mathrm{R} \& \mathrm{D}_{\mathrm{i}, \mathrm{t}-4}+0.4 \mathrm{R} \& \mathrm{D}_{\mathrm{i}, \mathrm{t}-5}+0.2 \mathrm{R} \& \mathrm{D}_{\mathrm{i}, \mathrm{t}-\mathrm{6}}\right)$

\subsection{Main regression model}

To test our hypothesis, we estimate the following logit regression model following Guo et al [22]: $\operatorname{Pr}($ Blockchain $=1)=\beta_{0}+\beta_{1}$ STRATEGY + $\beta_{2}$ PATENT $+\beta_{3}$ ABS_DA $+\beta_{4}$ LNRLAG $+\beta_{5}$ BIG4 + $\beta_{6} \mathrm{SIZE}+\beta_{7} \mathrm{ROA}+\beta_{8} \mathrm{LOSS}+\beta_{9} \mathrm{MTB}+$ $\beta_{10}$ LEVERAGE $+\beta_{11}$ TANG $+\beta_{12}$ OCF $+\beta_{13}$ RD + $\beta_{14} \mathrm{HHI}+$ Year FE + Industry FE $+\varepsilon$

In addition to the existing controls in Eq. (1), we control for the firm's fundamentals and performance, industry competition, and determinants of blockchain adoption from Guo et al [22]. Existing patents (PATENT) are measured as the natural log of total patents plus one. More patented technologies imply higher technological effort by a firm, and more likely the firm benefit from blockchain-related knowledge flow, and thus firms are more likely to adopt blockchain. Managerial discretion (ABS_DA) is calculated based on Modified Jones Model [68]. Firms with higher managerial discretion may adopt blockchain due to the technology hype without a clear understanding of the according to costs and risk. Audit delay (LNRLAG) is defined as the natural log of the number of days between audit opinion release and fiscal year-end. Higher audit delay indicates a more complex organizational structure. Blockchain could significantly improve efficiency for complex firms. We control external monitoring through the presence of a Big 4 auditor (BIG4). We control firm fundamentals by controlling log transformed assets

\footnotetext{
${ }^{2}$ The results remain quantitative and qualitative similar when we divide business strategy into three categories - prospector, analyzer, and defenders.

${ }^{3}$ we replace the dependent variable of Eq. (3) with the duration of the blockchain adoption, which equals the cumulative year of blockchain adoption, to investigate whether prospectors are more
}

(SIZE), firm debt to assets ratio (LEVERAGE), market to book ratio (MTB), operating cash flow (OCF), PP\&E to assets ratio (TANG), research and development expenses (RD), and control for firm performance by controlling firm income before extraordinary items to assets ratio (ROA) and occurrence of negative net income (LOSS). We also controlled for the industry competition level (Herfindahl-Hirschman Index, HHI) that the firm faces to control for the potential peer pressure on blockchain adoption. Year and FamaFrench 12 industry fixed effects are controlled to mitigate the impact of time-invariant year and industry characteristics.

\section{Empirical results}

In the propensity-matched sample, 208 of the sample firm adopt blockchain. Overall, $66 \%$ of the sample use Big 4 auditors. $66 \%$ of the firms earn a profit, and the median return on assets is 0.533 , indicating that most of the sample firms are profitable. On average, firms in the sample have a leverage ratio of 0.317 . With propensity score matching, the differences between prospector and defender are alleviated $(\mathrm{p}>0.1)$ and thus mitigate potential bias towards the covariant estimate. For Pearson correlation among variables, the STRATEGY is positively associated with blockchain adoption $(0.023, \mathrm{p}<0.01)$, indicating that prospectors are more likely to adopt blockchain. All significant pairwise correlations are less than 0.50 ; we also conduct multicollinearity tests and find that VIFs for the independent variables are well below 2.5. Therefore, multicollinearity should not be a concern in our setting.

Table 1 present the main regression results for the relationship between business strategy and blockchain adoption. In the first two columns, the estimated coefficient on STRATEGY is positive and statistically significant $(0.138, \mathrm{p}<0.05)$, indicating that prospectors are more likely to adopt blockchain. Further, we replace the STRATEGY variable with the binary variable PROSPECTOR and the result remains the same $(0.691$, $\mathrm{p}<0.1)$. Combined, the results support $\mathrm{H} 1$ that prospectors are more likely to adopt blockchain than defenders ${ }^{2}$. Consistent with prior studies, audit lag is positive and significantly associated with blockchain adoption, indicating that complex firms are more likely to gain competitive advantages from blockchain adoption. Patent and managerial discretion are positively associated with blockchain adoption ${ }^{3}$.

likely to early adopt blockchain than defenders. Untabulated results show that the positive and significant coefficient on both STRATEGY $(0.001, \mathrm{t}=2.345)$ and PROSPECTOR $(0.006, \mathrm{t}=$ 1.812) provide consistent results that prospectors are timelier in blockchain adoption than defenders even when both prospectors and defenders consider adopting blockchain. 
Comparing the means of technology efficiency of prospectors to the efficiency of defenders, defenders have statistically significantly higher mean of technology efficiency than prospectors (diff $=-0.019, \mathrm{t}$ $=-4.350, \mathrm{p}<0.01)$, consistent with the business strategy framework [1]. Further, as expected, Column (3) shows a negative significant coefficient on technology efficiency $(-62.464, \mathrm{p}<0.01)$, indicating a negative relationship between technology efficiency and blockchain adoption. The finding supports $\mathrm{H} 2$ that defenders who focus on technology efficiency are less likely to adopt blockchain than prospectors.

Table 1 Logit Regression - Analysis of Blockchain Adoption and Business Strategy

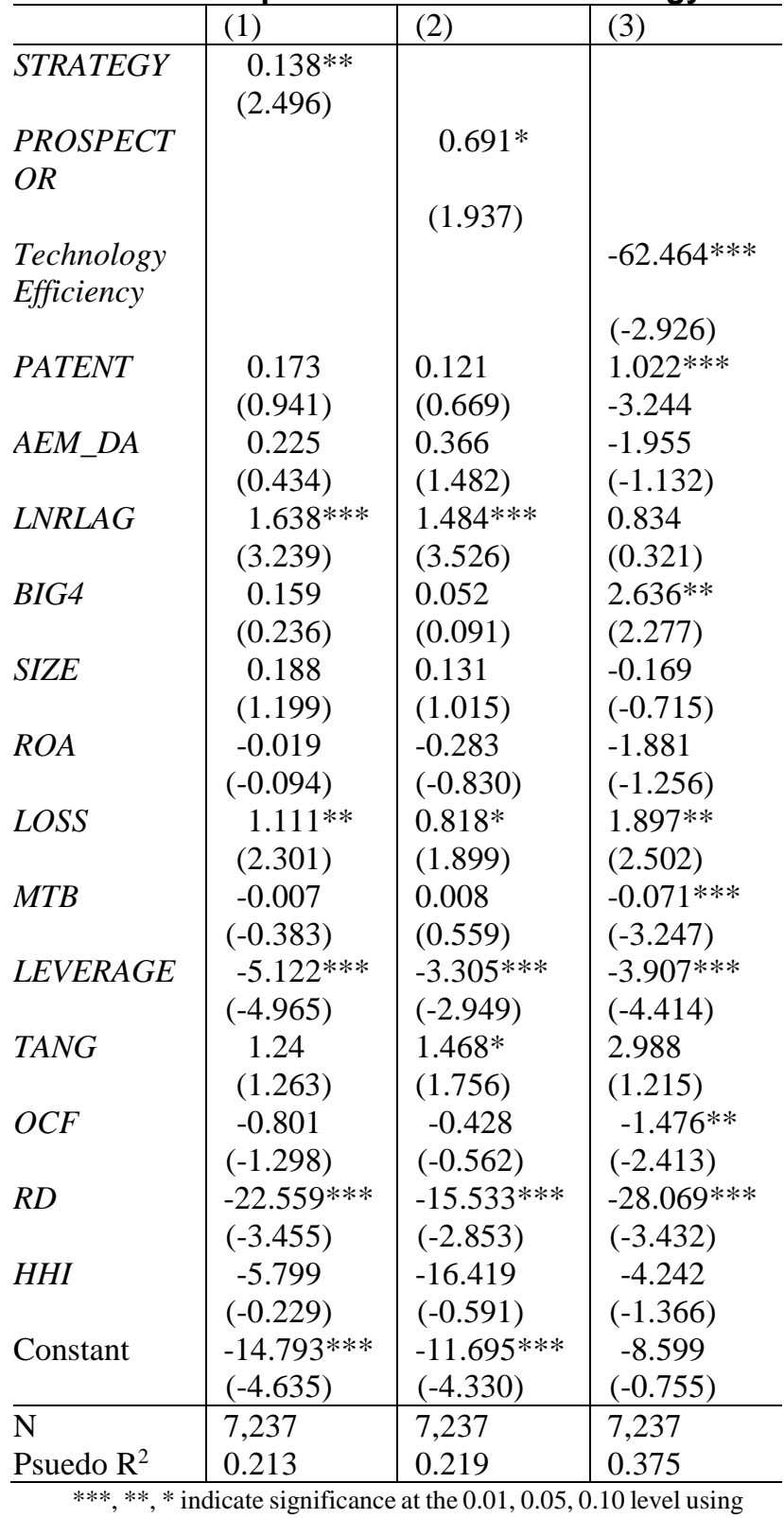

reported t-values based on heteroscedasticity robust standard errors adjusting for clustering at industry and year level. t-statistics are reported in parenthesis. Year and industry fixed effects are controlled.

\section{Additional analysis}

It is possible that there are omitted variables that are correlated with both business strategy and blockchain adoption, and thus causing endogeneity problems. We argue that the endogeneity problem is less likely in the study due to the consistency in firm business strategy [32]. Organizational theory [1] posits that when companies adopt a particular business strategy, the strategy should remain consistent over time. Consistently, prior literature also suggests that a firms' business strategy is determined at an early stage and remains relatively stable over time [27], [69]. Therefore, we expect prospectors and defenders have relatively stable STRATEGY scores over time.

Following Bentley et al [4], to examine the consistency of the sample firms' business strategy, we first analyze the variance of the STRATEGY measure within companies that have at least two consecutive years observations. Consistent with prior studies, untabulated results suggest that $5.71 \%$ of sample firms have STRATEGY scores that never change for the whole sample period, and the mean (median) variance of STRATEGY is $1.275(0.667)$. We then run the first difference for each firm-year STRATEGY score to determine how many times a company changes the score from year to year in the whole sample period. Untabulated results show that $43.79 \%$ of firm-year observations did not change scores from year to year (i.e. from 2018 to 2019), and $39.77 \%$ of firm-year observations change score by only one unit (i.e., changing from 24 to 23) from year to year. Less than 2 percent of firms change score by more than 3 unit-score. Further, the untabulated correlation between the current year STRATEGY and last year STRATEGY is positive and significant at 1 percent level (coefficient $=0.913, p$ $<0.001)$. In sum, consistent with organizational theory, the sample firms have a stable STRATEGY score over time, and thus a firm's business strategy could be treated as an underlying factor of blockchain adoption.

To assess whether STRATEGY represents a construct that provides incremental information than its six individual components, we conduct component analysis following Bentley et al (2013). First, we reestimated Eq. (1) with the six raw components of the STRATEGY measure but removed the RD variable due to multicollinearity issue with the RDS component in the STRATEGY score. The coefficients on all individual components are not significant (maximum $\mathrm{t}$ of the six components $=1.183$, maximum $\mathrm{p}<0.1$ ) and the components' signs are not always consistent with the sign of the composite STRATEGY measure. 
Further, we perform factor analysis on all six raw components of STRATEGY, and the results show that all items load on one factor. Consistent with the organizational theory which evaluates the components relative to industry competitors, we create factor scores of six raw components by industry-year, and re-estimate Eq. (1) by replacing the discrete dependent variable with the factor score. Coefficient on factor score remains positive and significant $(0.026, \mathrm{t}=2.987, \mathrm{p}<0.01)$.

Additionally, we conduct a placebo test to address the concern that our results might be driven by other unobservable factors that are not controlled in our specifications. We first randomly assign prospector groups and then re-estimate Eq (1) with RANDOM_ PROSPECTOR. If our main results are not driven by the business strategy but by other unobservable factors, we should observe a positive and significant coefficient on RANDOM_PROSPECTOR. If the driver is business strategy variation, we should not observe a significant coefficient on the RANDOM_ PROSPECTOR. To ensure this procedure is truly random, we repeat the random assignment procedure 1000 times.

The coefficient on RANDOM_PROSPECTOR is not significant, with maximum possible $t$-statistics equals to $-0.256(\mathrm{p}<0.1)$, indicating that the previously documented results are driven by business strategy variation, rather than the omitted factors that are not specified. Thus, the main result is robust to the placebo test, providing further support for the main findings.

\section{Conclusion}

This study investigates whether a firm's business strategy affects a firm's decision on blockchain adoption. We find that not only prospectors, who risktaking, innovation-oriented are more likely to adopt blockchain than defenders, who are efficiency-oriented. The results are therefore consistent with the RBV and business strategy theoretical framework. Main results remain consistent in the endogeneity test and factor analysis, and the placebo test shows insignificant results, providing additional support to the results.

Our study links three research literatures: the business strategy literature, RBV theory, and IT adoption/blockchain research. First, our study contributes to the business strategy literature by investigating how it can affect a firm's innovation and IT adoption choices. The results add a new context to the prior literature, where the focus is on how business strategy significantly impacts a firm's financial disclosure choice and operating activities, such as financial reporting irregularity, accounting conservatism, tax aggressiveness, and auditor's risk assessment [23], [31], [32], [41]. Complementing prior research which focusing on the impact of business strategy on financial disclosure, our study focuses on the impact of business strategy on firm's non-financial behavior, namely, firm's blockchain adoption decision.

Second, RBV theory [10] suggests that the variance of existing resources among firms result in heterogenous external opportunities among firms. Due to such variance of internal resources, the alignment between each external opportunity and firms' internal resources varies from firm to firm. Firms with higher alignment with a specific IT are more likely to pursue adoption. Our study extends RBV by combining its central ideas with the business strategy framework [1] the alignment between blockchain (external opportunity) and business strategy (internal resource) decides potential benefits that blockchain could bring to the firm, and thus affects firms' decision on blockchain adoption.

Third, prior blockchain literature either focuses on the effect of managerial opportunistic behavior related to blockchain, such as speculative blockchain disclosures or opportunistic blockchain-related name change[18], [70], instead of actual blockchain adoption, or provide internal and external factors that affects blockchain adoption, such as firm patent capability, agency costs, accounting complexity, and external monitoring effects from analysts and auditors [22]. Our study adds to the literature by focusing on the factor that is early determined at the beginning stage of a business, remains consistent over time, and affects every aspect of business fundamental structure and subsequent operating decisions [1], for instance, innovation strategy and IT adoption. Our results imply that, despite the internal and external factors documented in prior studies, business strategy may have already built firms' inherent characteristics at the early stage, influencing the fit between firms' business situation and blockchain, and hence affects firms' strategy on blockchain adoption.

Further, the study also has practical implications for managers to help them decide whether blockchain is suitable for the firm's current situation. Managers may need to consider the alignment between firms' current business strategy and blockchain when they make a decision on adoption. This study is also informative to investors on the risk and advantages of blockchain adoption, and what types of firms are more likely to adopt new technologies. This study also has implications for regulators by providing further understanding of blockchain application in business.

\section{References}

[1] R. E. Miles, C. C. Snow, A. D. Meyer, and H. J. Coleman Jr, "Organizational strategy, structure, and process," Acad. Manage. Rev., vol. 3, no. 3, pp. 546$562,1978$.

[2] R. Simons, "Accounting control systems and business 
strategy: an empirical analysis," Account. Organ. Soc., vol. 12, no. 4, pp. 357-374, 1987.

[3] R. Andrews, G. A. Boyne, J. Law, and R. M. Walker, "Centralization, organizational strategy, and public service performance," J. Public Adm. Res. Theory, vol. 19, no. 1, pp. 57-80, 2009.

[4] K. A. Bentley, T. C. Omer, and N. Y. Sharp, "Business strategy, financial reporting irregularities, and audit effort," Contemp. Account. Res., vol. 30, no. 2, pp. 780 $817,2013$.

[5] S. A. Zahra and J. G. Covin, "Business strategy, technology policy and firm performance," Strateg. Manag. J., vol. 14, no. 6, pp. 451-478, 1993.

[6] A.-M. Croteau and F. Bergeron, "An information technology trilogy: business strategy, technological deployment and organizational performance," $J$. Strateg. Inf. Syst., vol. 10, no. 2, pp. 77-99, 2001.

[7] P. P. Tallon, "A process-oriented perspective on the alignment of information technology and business strategy," J. Manag. Inf. Syst., vol. 24, no. 3, pp. 227268, 2007.

[8] P. Tallon, M. Queiroz, T. R. Coltman, and R. Sharma, "Business process and information technology alignment: construct conceptualization, empirical illustration, and directions for future research," J. Assoc. Inf. Syst., vol. 17, no. 9, p. 3, 2016.

[9] R. Cole, M. Stevenson, and J. Aitken, "Blockchain technology: implications for operations and supply chain management," Supply Chain Manag. Int. J., 2019.

[10] J. Barney, "Firm resources and sustained competitive advantage," J. Manag., vol. 17, no. 1, pp. 99-120, 1991.

[11] F. J. Mata, W. L. Fuerst, and J. B. Barney, "Information technology and sustained competitive advantage: A resource-based analysis," MIS Q., pp. 487-505, 1995.

[12] T. C. Powell and A. Dent-Micallef, "Information technology as competitive advantage: The role of human, business, and technology resources," Strateg. Manag. J., vol. 18, no. 5, pp. 375-405, 1997.

[13] V. Sambamurthy, A. Bharadwaj, and V. Grover, "Shaping agility through digital options:

Reconceptualizing the role of information technology in contemporary firms," MIS Q., pp. 237-263, 2003.

[14] M. Wade and J. Hulland, "The resource-based view and information systems research: Review, extension, and suggestions for future research," MIS Q., pp. 107-142, 2004.

[15] T. Ravichandran, C. Lertwongsatien, and C. Lertwongsatien, "Effect of information systems resources and capabilities on firm performance: A resource-based perspective," J. Manag. Inf. Syst., vol. 21, no. 4, pp. 237-276, 2005.

[16] S. Nakamoto and A. Bitcoin, "A peer-to-peer electronic cash system," Bitcoin-URL Httpsbitcoin Orgbitcoin Pdf, vol. 4, 2008.

[17] G. W. Peters and E. Panayi, "Understanding modern banking ledgers through blockchain technologies: Future of transaction processing and smart contracts on the internet of money," in Banking beyond banks and money, Springer, 2016, pp. 239-278.

[18] S. F. Cheng, G. De Franco, H. Jiang, and P. Lin, 'Riding the blockchain mania: public firms' speculative
8-K disclosures," Manag. Sci., vol. 65, no. 12, pp. 5901-5913, 2019.

[19] L. Pawczuk, J. Holdowsky, R. Massey, and B. Hansen, "Deloitte's 2020 global blockchain survey, from promise to reality," Deloitte Insights, 2020.

[20] S. Cao, L. W. Cong, and B. Yang, "Financial reporting and blockchains: Audit pricing, misstatements, and regulation," Misstatements Regul. June 2019, 2019.

[21] L. W. Cong and Z. He, "Blockchain disruption and smart contracts," Rev. Financ. Stud., vol. 32, no. 5, pp. 1754-1797, 2019.

[22] F. Guo, S. Walton, P. Wheeler, and Y. I. Zhang, "Early Disruptors: Examining the Determinants and Consequences of Blockchain Early Adoption," J. Inf. Syst.

[23] C.-C. Hsieh, Z. Ma, and K. E. Novoselov, "Accounting conservatism, business strategy, and ambiguity," Account. Organ. Soc., vol. 74, pp. 41-55, 2019.

[24] D. E. Schendel and C. W. Hofer, "A New View of Business Policy and Planning," Strateg. Manag. Boston Little Brown Boston, 1979.

[25] M. E. Porter, "Competitive Strategy, New York Free Press," PorterCompetitive Strateg., 1980.

[26] D. W. Beard and G. G. Dess, "Corporate-level strategy, business-level strategy, and firm performance," Acad. Manage. J., vol. 24, no. 4, pp. 663-688, 1981.

[27] D. C. Hambrick, "Some tests of the effectiveness and functional attributes of Miles and Snow's strategic types," Acad. Manage. J., vol. 26, no. 1, pp. 5-26, 1983.

[28] A. Ginsberg and N. Venkatraman, "Contingency perspectives of organizational strategy: A critical review of the empirical research," Acad. Manage. Rev., vol. 10, no. 3, pp. 421-434, 1985.

[29] J. G. March, "Exploration and exploitation in organizational learning," Organ. Sci., vol. 2, no. 1, pp. 71-87, 1991.

[30] M. Treacy and F. Wiersema, "How market leaders keep their edge," Fortune, vol. 131, no. 2, pp. 52-57, 1995.

[31] D. Higgins, T. C. Omer, and J. D. Phillips, "The influence of a firm's business strategy on its tax aggressiveness," Contemp. Account. Res., vol. 32, no. 2, pp. 674-702, 2015.

[32] Y. Chen, J. D. Eshleman, and J. S. Soileau, "Business strategy and auditor reporting," Audit. J. Pract. Theory, vol. 36, no. 2, pp. 63-86, 2017.

[33] E. Segev, "Strategy, strategy-making, and performance in a business game," Strateg. Manag. J., vol. 8, no. 6, pp. 565-577, 1987.

[34] E. Segev, "Strategy, strategy making, and performance-An empirical investigation," Manag. Sci., vol. 33, no. 2, pp. 258-269, 1987.

[35] S. A. Zahra and J. A. Pearce, "Research evidence on the Miles-Snow typology," J. Manag., vol. 16, no. 4, pp. 751-768, 1990.

[36] W. L. James and K. J. Hatten, "Further evidence on the validity of the self typing paragraph approach: Miles and Snow strategic archetypes in banking," Strateg. Manag. J., vol. 16, no. 2, pp. 161-168, 1995.

[37] J. Fisher, "Contingency-based research on management control systems: categorization by level of complexity," 
J. Account. Lit., vol. 14, p. 24, 1995.

[38] R. H. Chenhall and K. Langfield-Smith, "Performance measurement and reward systems, trust, and strategic change," J. Manag. Account. Res., vol. 15, no. 1, pp. 117-143, 2003.

[39] E. K. Lim, K. Chalmers, and D. Hanlon, "The influence of business strategy on annual report readability," $J$. Account. Public Policy, vol. 37, no. 1, pp. 65-81, 2018.

[40] R. Zhang, "Business strategy, stock price informativeness, and analyst coverage efficiency," Rev. Financ. Econ., vol. 39, no. 1, pp. 27-50, 2021.

[41] K. A. Bentley-Goode, N. J. Newton, and A. M. Thompson, "Business strategy, internal control over financial reporting, and audit reporting quality," Audit. J. Pract. Theory, vol. 36, no. 4, pp. 49-69, 2017.

[42] Y. Yuan, L. Y. Lu, G. Tian, and Y. Yu, "Business strategy and corporate social responsibility," J. Bus. Ethics, vol. 162, no. 2, pp. 359-377, 2020.

[43] M. Gosselin, "The effect of strategy and organizational structure on the adoption and implementation of activity-based costing," Account. Organ. Soc., vol. 22, no. 2, pp. 105-122, 1997.

[44] T. Blumentritt and W. M. Danis, "Business strategy types and innovative practices," J. Manag. Issues, pp. 274-291, 2006.

[45] L. J. Bourgeois III, "Strategy and environment: A conceptual integration," Acad. Manage. Rev., vol. 5, no. 1, pp. 25-39, 1980.

[46] B. Wernerfelt, "A resource-based view of the firm," Strateg. Manag. J., vol. 5, no. 2, pp. 171-180, 1984.

[47] G. Ray, J. B. Barney, and W. A. Muhanna, "Capabilities, business processes, and competitive advantage: choosing the dependent variable in empirical tests of the resource-based view," Strateg. Manag. J., vol. 25, no. 1, pp. 23-37, 2004.

[48] R. Sabherwal and P. Kirs, "The alignment between organizational critical success factors and information technology capability in academic institutions," Decis. Sci., vol. 25, no. 2, pp. 301-330, 1994.

[49] R. Sabherwal and Y. E. Chan, "Alignment between business and IS strategies: A study of prospectors, analyzers, and defenders," Inf. Syst. Res., vol. 12, no. 1, pp. 11-33, 2001.

[50] Y. E. Chan, R. Sabherwal, and J. B. Thatcher, "Antecedents and outcomes of strategic IS alignment: an empirical investigation," IEEE Trans. Eng. Manag., vol. 53, no. 1, pp. 27-47, 2006.

[51] G. Fenech, "Unlocking a \$200 Billion Dollar Collectibles Market on the Blockchain," Forbes Nov, vol. 8, p. 2018, 2018.

[52] H. Halaburda, "Blockchain revolution without the blockchain?," Commun. ACM, vol. 61, no. 7, pp. 27-29, 2018.

[53] Z. Fan, "Shareholder Value Implication of Blockchain Recordkeeping of Stock Ownership," 2019.

[54] J. Dai and M. A. Vasarhelyi, "Toward blockchain-based accounting and assurance," J. Inf. Syst., vol. 31, no. 3, pp. 5-21, 2017.

[55] M. Swan, "Blockchain thinking: The brain as a decentralized autonomous corporation [commentary]," IEEE Technol. Soc. Mag., vol. 34, no. 4, pp. 41-52,
2015.

[56] C. Holotescu, "Understanding blockchain technology and how to get involved," 14thInternational Sci. Conf. Softw. Educ. April, vol. 19, p. 20, 2018.

[57] L. Zavolokina, R. Ziolkowski, I. Bauer, and G. Schwabe, "Management, governance and value creation in a blockchain consortium," MIS Q. Exec., vol. 19, no. 1, pp. 1-17, 2020.

[58] D. F. Larcker, S. A. Richardson, and I. rem Tuna, "Corporate governance, accounting outcomes, and organizational performance," Account. Rev., vol. 82, no. 4, pp. 963-1008, 2007.

[59] J. Maniora, "Mismanagement of sustainability: What business strategy makes the difference? Empirical evidence from the USA," J. Bus. Ethics, vol. 152, no. 4, pp. 931-947, 2018.

[60] D. T. Otley and A. J. Berry, "Control, organisation and accounting," Account. Organ. Soc., vol. 5, no. 2, pp. 231-244, 1980.

[61] J. Dermer, Management Planning and Control Systems: Advanced Concepts and Cases. McGraw-Hill/Irwin, 1977.

[62] R. Sabherwal and S. Sabherwal, "How do knowledge management announcements affect firm value? A study of firms pursuing different business strategies," IEEE Trans. Eng. Manag., vol. 54, no. 3, pp. 409-422, 2007.

[63] D. F. Prawitt, N. Y. Sharp, and D. A. Wood, "Internal audit outsourcing and the risk of misleading or fraudulent financial reporting: Did Sarbanes-Oxley get it wrong?," Contemp. Account. Res., vol. 29, no. 4, pp. 1109-1136, 2012.

[64] M. Cheng, D. Dhaliwal, and Y. Zhang, "Does investment efficiency improve after the disclosure of material weaknesses in internal control over financial reporting?," J. Account. Econ., vol. 56, no. 1, pp. 1-18, 2013.

[65] F. Navissi, V. G. Sridharan, M. Khedmati, E. K. Lim, and E. Evdokimov, "Business strategy, over-(under-) investment, and managerial compensation," J. Manag. Account. Res., vol. 29, no. 2, pp. 63-86, 2017.

[66] L. K. Chan, J. Lakonishok, and T. Sougiannis, "The stock market valuation of research and development expenditures," J. Finance, vol. 56, no. 6, pp. 24312456, 2001.

[67] B. Lev, B. Sarath, and T. Sougiannis, "R\&D reporting biases and their consequences," Contemp. Account. Res., vol. 22, no. 4, pp. 977-1026, 2005.

[68] P. M. Dechow, R. G. Sloan, and A. P. Sweeney, "Detecting earnings management," Account. Rev., pp. 193-225, 1995.

[69] C. C. Snow and D. C. Hambrick, "Measuring organizational strategies: Some theoretical and methodological problems," Acad. Manage. Rev., vol. 5, no. 4, pp. 527-538, 1980.

[70] A. Jain and C. Jain, "Blockchain hysteria: Adding 'blockchain' to company's name," Econ. Lett., vol. 181, pp. 178-181, 2019. 